\title{
Marking of Building Materials at the Core of a Contract Price Transparency System
}

\author{
Dmitriy Silka \\ Department of Economics and Management in Construction \\ Moscow State University of Civil Engineering \\ Moscow, Russian Federation \\ silkadn@mgsu.ru
}

\begin{abstract}
One of the specifics of investment and construction projects is the difficulty of their planning and preparation stage. In order to make a contract it is necessary to have data on the costs of resources, work, equipment, etc. Transparency in these matters is necessary for both Russian and foreign companies considering the latter require Disclosure and Transparency Rules to be observed carefully. The paper shows advanced ways to collect information about construction resources, which can be effectively applied in resource planning.

It is important to consider that for implementation of investment and construction projects accurate planning of the need for materials is necessary. In order to perform effectively all the materials must be available on time. Moreover, there shouldn't be any surplus materials in the warehouse. All these require effective resource management.

The article proposes a mechanism for labeling goods, which must be extended to the sphere of building materials. The experience of foreign countries showed that at various times enterprises and government authorities took steps to introduce monitoring and labeling systems. Those projects continue to develop.

With the rapid development of information technology, there are more and more serious opportunities for commodity flow management improvement. Tracking goods from manufacturer to consumer minimizes both the number of operations connected with facilitating agencies and trading margins.
\end{abstract}

Keywords: cost, marking, monitoring, construction resources, construction

\section{INTRODUCTION}

The global changes that are happening today in the The marking of a wide variety of goods produced in the Russian Federation and imported from abroad is becoming increasingly widespread. Foreign suppliers must take into account the Russian specifics and meet the established requirements [1, 2]. In addition, an understanding of the essence of marking can allow Russian and foreign companies to benefit for themselves. In modern conditions, the scale of the spread of information technology, broadband communication channels, the Internet of things, the transition of public services to digital format and remote services is increasing [3]. This makes it possible to control the production and movement of almost any number of commodity items. In a number of areas, marking has already become mandatory. In other cases, it is introduced voluntarily, but with the prospect of becoming an integral part of the production and sale process. Russian Federal Law No. 487-FZ of December 31, 2017 established new rules on trade and cash desks, in particular, it is determined in relation to a number of goods that they cannot be sold and put into circulation if they are not marked. This marking allows saving the product code, by which the product can always be identified in the process of moving from producer to consumer. In this regard, the principles of marking were presented by an order of the Government of the Russian Federation No. 791-r dated April 28, 2018. The rules for its mandatory application have been introduced since 2019. The marking of goods has a great socio-economic effect as it allows ensuring the legality and, most importantly, transparency of production and movement of goods; creating unified product catalogs with their fixed parameters; implementing mechanisms of public control over the production and sale of goods; providing detailed information (prices, volumes of production and supplies, units of measurement, etc.) on goods for interested parties. Direct marking also ensures transparency of contract prices of both public and commercial procurement, provided that the commodity items are included in the monitoring and marking system, and these products are used for public and commercial procurement.

When performing public procurement, there is a big problem of their effectiveness. For example, according to the Accounts Chamber of Russia, the volume of construction in progress as of the 3rd quarter of 2019 exceeded 5 trillion rubles. Thus, the problem of project management and their cost is extremely relevant. Nowadays, dozens of objects are not commissioning on time. They are postponed to next year. Despite the measures taken by the relevant departments, as a rule, the facilities are not completed even within one year. The problem concerns about half of the Federal Targeted Investment Program of Russia (FTIP). The amount that today 
is total for both open and closed items, which relate to unfinished objects, is 5.3 trillion. rub. And this is just one of the programs. There are many commercial projects, individual projects as part of federal and regional procurement, etc., which increase the scale of the problem. The basis of this is the unreliable estimated cost, which subsequently forms the basis of budgets, etc. At the conclusion of the contract, the parties make preliminary estimates based on reference data and collections of price indicators. In conditions of inflation, rising wage levels, price indices and current indicators of the resource values are not updated with the proper frequency. When this happens systematically, the problem is compounded with acceleration. The actual consequences of such processes have led to the growth of unfinished construction, which the Accounts Chamber of the Russian Federation speaks of. A critical level of deviations at the estimated construction price is actually allowed at the preinvestment stages. This requires measures to improve the quality of reference materials on the current cost of resources and other parameters.

Nowadays, only 10 groups of products are subject to mandatory marking in accordance with the Order of the Government of the Russian Federation No. 792-r of April 28, 2018, and they fragmentarily represent sectors and spheres of the national economy. In the near future, the Ministry of Industry and Trade of the Russian Federation should begin to address issues of expanding the list of marked goods and the substantiation of selected groups of marked goods, the effectiveness of relevant projects, etc. However, there are many questions, including substantiation of the need to mark specific lists of goods, industry affiliation of goods with priority for marking, codification of goods, where the number of items is hundreds of thousands. And other issues that arise concomitantly with the first ones. In this regard, the relevance of the topic of the paper is not in doubt, and the analysis of these issues has a huge overall economic effect.

\section{LITERATURE REVIEW AND RESEARCH METHODS}

The analysis of literary sources indicates the presence of a large number of works in these areas $[4,5]$. The Ministry of Industry and Trade of the Russian Federation and the project operator are working on improving and finalizing business processes, within the framework of which optimal solutions for marking are developed. The marking is a complex project that transforms the market and takes it to a new digital level. The first steps in its implementation have already been taken. The processes and issues of introducing marking, the degree of readiness of manufacturers and retailers, auxiliary resources for large-scale changes are actively studied by many authors $[6,7]$. In connection with the expansion of the spread of the concept of marking, researchers are revealing new concepts introduced into the economy, monitoring rules, rights and obligations of participants [8]. The authors of [9] note the need for a thorough study of the marking itself. It is indicated that the smallest errors even in the label itself have serious consequences. Another study [10] says that according to official statistics from the Russian Federal State Statistics Service (Rosstat), the turnover of illegal products approached 3 trillion rubles in 2017. This amount of counterfeit inflicts significant blow to the country's economy and legal business. To combat the shadow economy, the government decided to create a national system for digital marking and traceability of goods. There are pilot projects, but many questions remain about how a uniform system of mandatory marking will be implemented and function. The research is also being conducted actively with respect to goods imported from abroad. The paper [11] considers the problems of identifying counterfeit and falsified goods in foreign trade (using the example of the Far Eastern region). Statistical data on the turnover of counterfeit and falsified goods in Russia is analyzed; the role of the customs service in identifying counterfeit and falsified goods is studied; the value of marking is determined to protect against falsification of products, recommendations aimed at improving this type of activity are offered.

Studies examine trends, and their authors conclude that all work on tracking goods should be universal. To achieve this goal by 2024, a unified system of product marking should start to function. It is assumed that both new and already marked products will have to be included in a single catalog created by the Center for Development of Advanced Technologies (CDAT) under the PPP framework. The information system will store all the information generated by the participants in the marking project. For this, the center creates a unified national system of marking and traceability of goods - Chestny ZNAK (Honest SIGN). The formation of a unified register of identification tools is also provided for at the EAEU level: it will include a description of identification tools and their characteristics used for marking goods in the union.

The next question after the very fact of organizing traceability of goods is monitoring the movement of goods [12]. The author points out that the focus is not on any logistics operator, but on the integrated digital platform mentioned above. Risk management issues are also considered. The paper [13] contains an analysis of violations of customs legislation when crossing the state border. The main attention is paid to creating a risk profile, substantiating its structure and the possibility of identifying goods based on the use of information provided by the customs declaration, as well as marking of goods. Due to the fact that the Chestny ZNAK information system for marking and traceability of goods is becoming the source of a wide variety of analytical information, researchers are working on the principles of obtaining the sought information, its interpretation and optimization [14].

\section{RESULTS}

An analysis of the current marking system shows that the products to be marked are selected experimentally. There are justifications for such a choice, but the specific economic effect is not calculated. It is necessary to approach the marking process through the solution of certain industry problems. In this case, the effects of marking can be expressed more accurately. According to the topic of the paper, marking can solve the problem of transparency of contract prices. To conclude construction contracts, the initial maximum contract price is calculated. To do this, it is necessary to use the estimated standards for the price of construction (repair, 
reconstruction, etc.), and information on the current cost of construction resources is needed in the corresponding calculations. To obtain information on the cost, the Ministry of Construction of the Russian Federation organized the Federal State Information System of Pricing in Construction (FSIS PC) in 2016. The principle of operation of this system is as follows. According to the urban planning code, manufacturers of building materials must interact with this system and, on the basis of a qualified digital certificate for electronic signature, connect to it and regularly transmit all information about the current value of manufactured goods, equipment, machines and mechanisms. At the end of October 2019, 14,682 legal entities were registered in the FSIS PC, and there were 117,441 entries in the resource catalog. The catalog is organized as follows. All construction resources are divided into 27 groups. There are 11 equipment groups. One group for machines and mechanisms. To operate the system, enterprises must report on all produced positions, and in the absence of feedback from them, they face a fine. At the same time, it is not possible to verify the completeness of the information, its reliability. The stringency of the system of access to the transmission of information is not the stringency of the work itself. In addition, enterprises must spend labor and other resources on regular work with the system, but the corresponding costs are not compensated for. In March 2019, the system was only $13 \%$ full. Therefore, its launch in industrial operation was postponed to 2022 .

In connection with the above, it should be noted that the marking system can be called an alternative way of collecting information about the cost of construction resources and hypothetically assume that it will have beneficial differences:

1) for the organization of the marking system, one-time relatively large costs are assumed, which involve automation of the process. Then the costs are significantly minimized;

2) resources are mandatory included in the monitoring system if they are produced and shipped to dealers and customers;

3) enterprises cannot make mistakes, show reluctance to transfer information to the system, fail to meet deadlines, etc.;

4) if FSIS PC involves manual processing of data on the side of the enterprise or some automation through accounting systems, for example, $1 \mathrm{C}$, is possible, then there is no guarantee of protection against incompleteness and information errors. And in general, such an approach does not meet the necessary and sufficient modern principles of the digital economy. If we hypothetically assume that the FSIS PC is connected to the accounting systems of manufacturers, then it is extremely difficult to do this, since this creates a complex management system, ensuring the smooth operation of the system, legislative determination of this order, large investments in finalizing $1 \mathrm{C}$ and all other similar systems, etc. If we consider that the issue concerns both small enterprises and private entrepreneurs, for which investments are extremely limited, and the state clearly does not aim to direct budget funds to these projects, then the whole idea of ensuring the compliance of the FSIS PC with the digital economy is even more complicated.
On the contrary, product marking is devoid of all the disadvantages outlined above. The advantages of this system also lie in the fact that this is not an industry solution, but a general business solution. As a result, the effect of the scale of production reduces the load on the local participants of the system to the greatest extent. In this regard:

1) in order to connect to the marking system, enterprises do not need to contact any purely branch departments. On the contrary, there is a general procedure for ensuring marking and a common state infrastructure - the system operator, software, legislation, national catalog, etc.;

2) accounting for the movement of goods also takes place on the basis of the general economic infrastructure - online cash desks, workflow standards, data exchange protocols;

3) enterprises and their products fall into catalogs accessible to everyone, and they can also be presented in specialized catalogs, which, for example, are downloaded separately for the purposes of rationing and pricing in construction.

4) the problem of the construction industry is that not always used resources, as well as work and services can be accurately described as purely construction ones. For example, air conditioners used for indoor climate control, glass, paints, electrical equipment, etc. In the example with marking, these problems are smoothed over, since monitoring is carried out not only for construction (as in the FSIS PC) but for all possible tasks in the economy.

In addition to the arguments presented, there are other reasons for applying the marking system in the field of building materials. It is known that the concept and principles of marking are developed by the Ministry of Industry and Trade of the Russian Federation. In 2015, the Ministry was given the authority to implement state policy in the building materials industry, which was previously dealt with by the Ministry of Construction of Russia [15]. About 0.5 million people are employed in this industry. The Ministry of Industry and Trade of the Russian Federation has already begun certification of goods, financial support of manufacturers in order to ensure the growth of the industry. It was possible to achieve a two-fold reduction in the Russian-made low-quality and unsafe cement that was on the market. Since 2018, the procedure for mandatory confirmation of compliance began to be applied to thermal insulation materials, building mixtures and heating radiators. There is an uneven loading of production capacities $[16,17]$. For cement, roofing, waterproofing and non-metallic materials, prefabricated reinforced concrete, for heat-insulating and asbestos-cement products, the average load of enterprises is from 45 to $60 \%$. In neighboring regions, there are often overlapping capacities where it is economically feasible not to compete, but to cooperate. To eliminate these structural imbalances, the Ministry of Industry and Trade is completing work on creating an interactive map of the building materials industry. It will be placed in the GIS Industry at free access.

Thus, we see that the Ministry of Industry and Trade of the Russian Federation is also actively involved in the problems of 
building materials. Accordingly, the extension of marking to this industry is within the competence of decision makers.

\section{DISCUSSION}

There are many questions to those ten groups of products that are subject to mandatory marking, which are discussed by the professional community. The new system has many tasks and problems that need to be addressed. The system is developing, and this is a normal evolutionary process. For each individual type of product, its own nuances are provided for marking and accounting for the movement of resources. To solve problems at the level of building materials, professional communities of builders in the form of unions, associations, self-regulatory organizations that will participate in the selection of those resources for which marking has the highest priority should join the work. In this case, it will be possible to make assessments of the usefulness and effectiveness of marking in an industry-specific way.

As mentioned above, the catalogs of all construction resources that can be used in construction are formed in the FSIS PC system. Moreover, the number of private codes for each resource exceeds one hundred thousand. And the amount of resources in the system will always only increase. As part of the marking system, which is implemented by the Ministry of Industry and Trade of the Russian Federation, its own marking system is used, which is also not fully developed. So, for example, the OKPD 2 classifier (the all-Russian classifier of products by economic activity) is taken as the basis. This classifier is used to generate a product code, which is also used to formulate a schedule for placing orders in the unified information system of government procurement. This classification system allows implementing such mechanisms as:

1) reverse search for the name of the product or type of service by their code;

2) simultaneous contextual search of the product code by three classifiers at once: by OKPD 2 and by OKDP and OKPD that are archived since 2017 ;

3) viewing registers, data lists and analytical reports;

4) the implementation of services for the formation of a (local) personal directory of OKPD 2 codes, the description of which provides examples of optimal and unsuccessful search queries and much more.

At the same time, when the issue concerns industry solutions, for example, construction, it can be noted that the system of regulatory documents presupposes other principles of codification of resources. In the estimated normative base of pricing in construction, there are standards and prices for individual works, which include direct costs determined by the formula:

$$
D C=W+M+O M
$$

where $\mathrm{W}$ - the wages of construction workers, $\mathrm{M}$-materials, $\mathrm{OM}$ - the cost of operating construction machines and mechanisms (including the wages of workers controlling machines).

This shows that the materials and, consequently, their codes run through algorithms for determining value. The material code is compared with a certain work in the catalog, and its change entails a number of changes in other documents, which cannot be done without critical consequences. If we deploy a full-scale monitoring system for the building materials industry, then it is necessary to solve the problem of creating a codification system that will satisfy both the tasks of marking throughout the country and the tasks of estimated rationing and pricing during construction, repair, reconstruction, and liquidation of a piece of real estate.

\section{CONCLUSION}

The building materials industry in the Russian economy is represented by a large assortment of Russian and especially foreign resources. The Russian economy needs an influx of foreign investment, and therefore, it is necessary to continue work to improve the investment climate. The paper reveals ways to improve this climate when implementing measures by federal authorities and professional communities and associations. Construction companies have a difficult task of obtaining the actual prices for construction resources for the planning and implementation of construction projects. The paper presents an intersectoral system for marking and subsequent monitoring of construction resources, which has great potential for the industry and increases the efficiency of planning, implementation and control of construction projects. The proposed system requires serious work on it, while a centralized approach by the state allows effectively offering proven solutions in all sectors. The implementation of the marking system in construction, as well as in other industries, can be carried out in stages, without the need for large-scale changes and reforms in the economy.

\section{REFERENCES}

[1] M. I. Kamenetskii and N. Y. Yaskova, "Construction and real estate markets: from crisis to growth", Studies on Russian Economic Development, 2018, T. 29, no. 1, pp. 35-40.

[2] D. Silka, "Modern methods of cost saving of the production activity in construction", IOP Conference Series: Earth and Environmental Science, Ser. Energy Management of Municipal Transportation Facilities and Transport, EMMFT 2017, 2017, 012155 p.

[3] S. C. Madala, S. S. Asadi, and D. S. Chandra, "Critical study of the technological interventions on the evaluation of affordable housing to be implemented under PMAY", International Journal of Recent Technology and Engineering, April, 2019, vol. 7, issue 6C2, pp. 270 277.

[4] T. Kitahara, K. Satou, and J. Onodera, "Marking robot in cooperation with three-dimensional measuring instruments", ISARC 2018 - 35th International Symposium on Automation and Robotics in Construction and International AEC/FM Hackathon: The Future of Building Things, 2018.

[5] T. Tsuruta, K. Miura, and M. Miyaguchi, "Mobile robot for marking free access floors at construction sites", Automation in Construction, November 2019, vol. 107. DOI: 10.1016/j.autcon.2019.102912.

[6] S. V. Korablev, "Marking of goods and the fate of small business", In the collection: Information as an engine of scientific progress, 
[13] A. K. Modenov, M. P. Vlasov, and A. A. Boboshko, "Formation and application of a risk profile in the identification of goods", The Petersburg Economic Journal, 2019, no. 1, pp. 7-14. practical conference, Sterlitamak, 2019, pp. 190-193.

[7] "Marking. Totally agree!", Standards and quality, 2019, no. 6, pp. 7173.

[8] L. V. Andreeva, "Legal regulation of marking of goods by means of identification in electronic form", Yurist (Lawyer), 2019, no. 3, pp. 20 27.

[9] I. Demin and G.Schalk, "Reliable product marking: three tips from the csb-system", Pererabotka moloka (Milk processing), 2019, no. 2 (232), pp. 10-11.

[10] "Marking is a digital code of honest business", Molochnaya promyshlennost (Dairy industry), 2019, no. 1, pp. 14-16.

[11] T. V. Chadova and N. V. Berlova, "Problems of identifying counterfeit and falsified goods in foreign trade", Bulletin of the Russian Customs Academy, 2019, no. 1, pp. 85-90.

[12] A. V. Dmitriev, "Digital technologies of cargo traceability in transport and logistics systems", Strategic decisions and risk management, 2019, vol. 10, no. 1, pp. 20-27.
[14] Yu. A. Nalivaiko and N. A. Denisova, "Analysis of the implementation of the project of launching mandatory marking of drugs", Bulletin of the International Scientific Surgical Association, 2019, vol. 8, no. 1, pp. 30-33.

[15] "The Ministry of Industry and Trade of the Russian Federation brought 2.5 billion rubles to the construction industry", Building Business News Agency [Electronic resource]. Available at: http://ancb.ru/publication/read/5928 (Accessed: 26 October 2019).

[16] L. Gerasimova and D. Silka, "Concept of costs management with environmental protection functions", International Science Conference SPbWOSCE-2018 "Business Technologies for Sustainable Urban Development", E3S Web Conf., 2019, vol. 110.

[17] V. Kankhva, "Using the entropy of cover method in the analysis of investment risks", MATEC Web of Conferences, January 2018, no. 212 (2), 08003 p. 